Ronald D. Seegobin MRCP FRCPC, * Frank C. Goodland, $\dagger$ Trevor H. Wilmshurst PhD, $\ddagger$ James Johnston, $\S$ Chris Wainwright fFarcs, * John Norman PhD FFarCs, * Neville Conway FRCP

\title{
Postoperative myocar- dial damage in patients with coronary artery disease undergoing major non cardiac surgery
}

\begin{abstract}
A prospective study was carried out in a group of 50 patients with coronary artery disease, presenting for major non-cardiac surgery, to investigate the timing and incidence of further perioperative myocardial damage. A standardised anaesthetic was used. A standard 12-lead ECG was taken immediately before surgery and at 24, 48, and $72 \mathrm{hr}$ after the start of anaesthesia. Blood samples were taken immediately preoperatively and at 6, 24, 48, and $72 \mathrm{hr}$ after anaesthesia for total $C K$ and CK-MB assay. Thirty-three patients (66\%) showed ECG evidence suggestive of further infarction, and of these, two (4\%) died in the immediate perioperative period. The first ECG change occurred in $27 / 31$ (87\%) by $24 \mathrm{hr}$, in $3 / 31$ (10\%) by $48 \mathrm{hr}$, and $1 / 3 \mathrm{l}(3 \%)$ by $72 \mathrm{hr}$. Twenty-nine patients (58\%) including the two deaths showed CK-MB enzyme changes. The first elevation in CK-MB was nil at $6 \mathrm{hr}$ and $72 \mathrm{hr}$, with 23/27 (85\%) at $24 \mathrm{hr}$, and $4 / 27$ (15\%) at $48 \mathrm{hr}$. In 22/50 (44\%) ECG and enzymes were correlative. Goldman and Cooperman risk indices were calculated for each patient. The Cooperman risk index was superior to the Goldman scale in the correlation of observed with predicted myocardial morbidity. Patients with $E C G$ changes only before surgery were just as liable to further myocardial damage as those patients with ECG changes and a documented history of a previous infarct andlor symptoms.
\end{abstract}

\section{Key words}

COMPLICATIONS: myocardial infarction;

HEART: ischaemia;

MONITORING: electrocardiography.

From the Departments of Anaesthesia,* Cardiology, $\S$ Chemical Pathology, $†$ Electronics, $\ddagger$ University of Southampton, Southampton General Hospital, Southampton, England SO9 4XY. Department of Cardiology, § University of Oxford, Oxford, England.

Address correspondence to: Dr. R. Seegobin, Department of Anaesthesia, Queen's University, Kingston, Canada K7L 3N6. Accepted for publication 3rd June 1991.
Myocardial damage is maximal in the first $24 \mathrm{hr}$ after surgery, and may not be adequately predicted by current risk indices.

Nous avons entrepris une étude prospective de l'incidence et de l' histoire naturelle de nouvelle lésion myocardique survenant en période périopératoire chez 50 coronariens lors d' une intervention chirurgicale majeure autre que cardiaque. L'anesthésie se déroulait de façon conventionnelle mais on faisait un ECG à 12 dérivations juste avant et 24,48, et 72 h après le début de l'anesthésie. On prélevait du sang au mêmes moments de même qu'à 6 h après le début de l'anesthésie afin de mesurer les $C K$ totales et la fraction $C K-M B$. Trente-trois patients (66\%) ont présenté à l'ECG une évidence d'infarctus nouveau et deux d' entre eux (4\%) sont décédés en péri-opératoire immédiat. Les premiers signes électrocardiographiques d'infarctus étaient présents à $24 \mathrm{~h}$ chez $27 / 31$ parients $(87 \%)$, à $48 \mathrm{~h}$ chez $3 / 3 \mathrm{I}$ (10\%) et à 72 h chez $1 / 31$ (3\%). Chez vingt-neuf patients (58\%), dont ceux qui sont décédés, il y eu augmentation des $C K-M B$ qui s'est d'abord manifesté chez les survivants à 24 h dans $23 / 27$ cas (85\%) et à $48 \mathrm{~h}$ dans $4 / 27$ cas (15\%). Vingt-deux patients (44\%) eurent à la fois une altération électrocardiographique et une augmentation des $C K-M B$. On a calculé les scores de risque de Cooperman et de Goldman et le premier prédisait mieux que le second la morbidité myocardique observée. La présence d' une histoire de problème cardiaque n' alourdissait pas le pronostic sombre d'un ECG préopératoire anormal. Le myocarde est maximalement à risque en deça de $24 \mathrm{~h}$ d'une intervention chirurgicale et les scores de risque le sous-estiment souvent.

Patients with a history of coronary artery disease are at increased risk of further myocardial infarction when presenting for major non-cardiac surgery. The incidence of further myocardial damage in patients with ECG changes suggestive of coronary artery disease but no previous documented infarction remains unknown. The induction of anaesthesia and intubation of the trachea can be associated with change in both blood pressure and heart rate, often leading to an increase in the rate pressure 
product, and this could cause further myocardial damage ${ }^{\prime}$ by increasing myocardial oxygen demand.

The immediate perioperative period can be an extreme challenge to the cardiovascular system, mediated by endocrine changes, ${ }^{2-4}$ and may result in an imbalance of myocardial oxygen supply and demand, due to increases in heart rate, blood pressure, shivering, and increased peripheral vascular resistance. The true incidence of such occurrences remains unknown, as the classical sign of chest discomfort may be masked at induction and in the perioperative period. Previous studies have relied on subjective symptoms or investigations as clinically indicated to diagnose perioperative infarction. ${ }^{5-7}$ On this basis reinfarction was found to be maximal on the third post-operative day, ${ }^{5}$ the reinfarction rate was higher if surgery was performed in the six months after an infarction, ${ }^{6}$ and risk indices have been described. ${ }^{7.8}$ However, myocardial damage may be asymptomatic and be evidenced by changes in serial ECG and or cardiospecific enzymes in the absence of ECG changes. New damage may be on the borders of previous damage and not be recognised by the standard 12-lead ECG. The timing of such silent damage is not known.

This prospective study was designed to assess the incidence of further early myocardial damage, by serial cardiospecific CK-MB enzyme assay, and serial standard 12-lead ECGs in the $72 \mathrm{hr}$ after anaesthesia and surgery, in a group of patients who had a history or ECG changes suggestive of coronary artery disease, presenting for major non-cardiac surgery.

\section{Methods}

\section{Patient selection}

The study was approved by the Hospital Ethics Committee and informed written consent was obtained from all patients. Fifty patients of both sexes, ASA physical status Il to IV with either a documented history of previous myocardial infarction with or without residual ECG changes or angina with or without ECG changes, or ECG changes alone, and presenting for major non-cardiac surgery at the Royal South Hampshire Hospital, University of Southampton, were admitted into this prospective study. Patients with a bundle branch block or on medical therapy liable to affect the ST segment were excluded.

\section{Study design}

Patients continued with their current medical therapy. On the day of surgery a standard 12-lead ECG was taken and Holter monitoring applied to the patient, starting one hour before induction of anaesthesia. The continuous ECG was recorded either from modified leads $V I$ and $V_{5}$ (30 patients), or 16 precordial leads multiplexed on to one channel and a modified lead I (twenty patients), on to a two-channel Oxford Medilog 2 Frequency modulated (FM) recorder. Detailed results of this ECG monitoring are reported in an accompanying paper. ${ }^{9}$ Preoperatively, blood was analyzed to ensure that haemoglobin and serum electrolyte concentrations were within the normal range. All patients received a standardised premedication regime of diazepam $10 \mathrm{mg}$, and metoclopramide $10 \mathrm{mg}$, orally two hours before surgery, and a standardised general anaesthetic technique. On arrival in the anaesthetic room, each patient's blood pressure was recorded non-invasively using a Bard Sentry non-invasive blood pressure monitor, with a thermal printer, at two-minute intervals during induction of anaesthesia, at three-minute intervals during surgery and at five-minute intervals thereafter for the next $24 \mathrm{hr}$.

Appropriate intravenous lines were inserted, and after three minutes of denitrogenation, anaesthesia was induced with fentanyl $3 \mu \mathrm{g} \cdot \mathrm{kg}^{-1}$, thiopentone $4 \mathrm{mg} \cdot \mathrm{kg}^{-1}$, and succinylcholine $1.5 \mathrm{mg} \cdot \mathrm{kg}^{-1}$. After tracheal intubation, anaesthesia was maintained by controlled ventilation using a Bain circuit with a fresh gas flow of $70 \mathrm{ml} \cdot \mathrm{kg}^{-1}$ of nitrous oxide and oxygen in 2:1 ratio, a tidal volume of 10 $\mathrm{ml} \cdot \mathrm{kg}^{-1}$ and a respiratory rate of $12 \mathrm{~min}^{-1}$. Normocapnia under anaesthesia was ensured using a Hewlett Packard non-invasive capnometer and was verified with arterial blood gas analysis. Neuromuscular blockade was achieved with alcuronium $0.25 \mathrm{mg} \cdot \mathrm{kg}^{-1}$, with a quarter of the initial dose used for subsequent maintenance of paralysis. Fentanyl was thereafter as clinically indicated in increments of a quarter of the initial dose, and halothane or enflurane used as adjuvants to provide anaesthesia. Blood was replaced as lost. At the end of anaesthesia patients either neuromuscular blockade was reversed with atropine and neostigmine or lung ventilation was continued as clinically indicated. Prior to induction of anaesthesia, and at intervals of $6,24,48$, and $72 \mathrm{hr}$, blood was drawn for total CK and CK-MB fraction assay. The EDTA sample was spun within one hour, and the serum deep frozen for later batch assay. At 24,48 , and $72 \mathrm{hr}$ the standard 12-lead ECG was repeated and haemoglobin and electrolyte analyses were repeated to ensure a normal range. All patients were in an ICU environment for the first $24 \mathrm{hr}$ after surgery and received supplementary oxygen by face mask at $4 \mathrm{~L} \cdot \mathrm{min}^{-1}$ in the $24 \mathrm{hr}$ after surgery. Analgesia was maintained in the $24 \mathrm{hr}$ after surgery, with a titrated iv morphine infusion with a Vickers infusion pump, adjusted by the clinical staff as necessary. The tracheas of all patients in this study were extubated within six hours of the start of anaesthesia. Holter and non-invasive blood pressure monitoring was discontinued at $24 \mathrm{hr}$. 


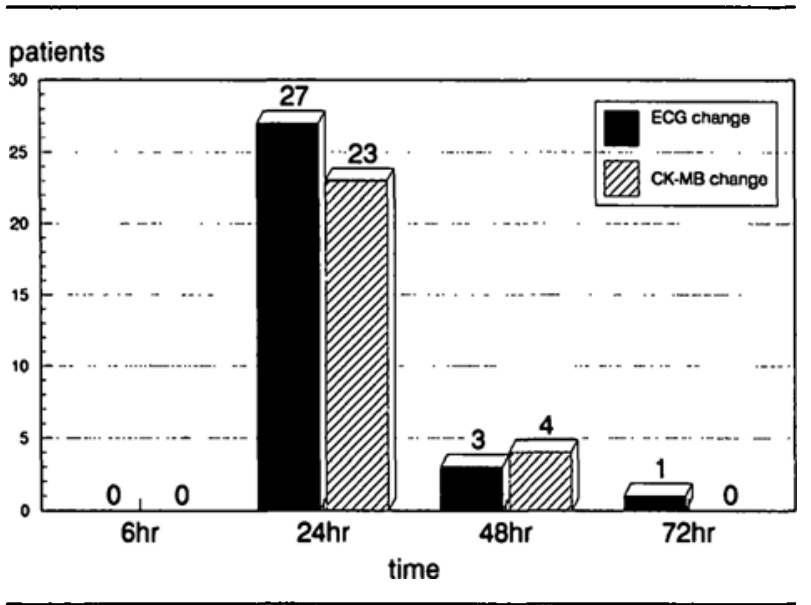

FIGURE 1 Histogram of timing of first ECG and/or CK-MB change. Note the absence of CK-MB change at $6 \mathrm{hr}$. Although the majority of abnormalities were evident by $24 \mathrm{hr}, 13$ to $15 \%$ of changes were not seen until 48 to $72 \mathrm{hr}$.

\section{Laboratory tests}

Haemoglobin and electrolytes were measured as a routine in our hospital laboratory. The serum for total $\mathrm{CK}$ and CK-MB assay was stored at $-20^{\circ} \mathrm{C}$, and analyzed using batch assay with a Boehringer Mannheim immunoassay total CK and CK-MB NAC activated kit. Serum CK-MB was considered pathologically elevated, and indicative of myocardial damage, at $>12 \mathrm{I} \cdot \mathrm{U} \cdot \mathrm{L} \cdot{ }^{-1}$, independent of serum CK level, which is elevated after surgery. Each sample was assayed three times. All standard 12-lead ECGs were recorded with a Hewlett Packard Pagewriter. The standard 12-lead ECG at $24 \mathrm{hr}$ was recorded after the Holter continuous ECG monitoring system was removed. $Q$ wave infarction was based on the appearance of new $Q$ waves, $>40 \mathrm{msec}$, and $>25 \%$ of ensuing $R$ wave. Non $Q$ wave infarction was based on persistent ST change $>2$ $\mathrm{mm}$ and or symmetrical $\mathrm{T}$ wave inversion for at least $48 \mathrm{hr}$ duration. From the preoperative history and investigations, using the criteria of both Goldman ${ }^{10}$ and Cooperman, ${ }^{8}$ the relative risk of further myocardial damage for each patient was assessed, and each patient was assigned to the relevant risk class.

\section{Statistical analysis}

For each risk class in each classification scheme, the incidence of expected complications was calculated. For each risk class the incidence of observed complications was compiled from new ECG changes, CK-MB enzyme changes and combined new ECG and CK-MB changes. Comparison between observed and expected myocardial damage for each risk class was performed using the Chi square test with the Yates correction factor. The difference in further damage between patients with a docu-
TABLE 1 Types of operations

\begin{tabular}{lr}
\hline Vascular (42) & 22 \\
aorta & 15 \\
fem pop & 5 \\
carotid & \\
Others (8) & 3 \\
upper abdominal & 2 \\
lower abdominal & 3 \\
peripheral & \\
\hline
\end{tabular}

mented history of previous myocardial infarction and those with ECG changes alone, and those with and without diuretic therapy was also analysed using the Chi square test.

\section{Results}

Table I shows the breakdown of operations. There were eight women and 42 males in this study. Ages ranged from 39 to 72 with a mean of $61.5 \mathrm{yr}$. Total anaesthesia time ranged from 55 to 225 min with a mean of 122.3 . Twenty-nine patients (58\%) showed elevated CK-MB assay. Thirty-three patients $(66 \%)$ showed ECG changes. Two patients $(4 \%)$ died in the immediate post-surgery period with concurrent ECG and cardiospecific enzyme changes. Both cases were emergency operations in ASA physical status IV patients, each of whom gave a history suggestive of a myocardial infarction in the month before surgery. One patient had an emergency partial gastrectomy for a large bleeding ulcer. She had an episode of left ventricular failure $48 \mathrm{hr}$ before surgery. The second patient had an aortobifemoral graft for acutely ischaemic legs. He had experienced an episode of chest pain with left ventricular failure in the week before surgery.

Figure 1 shows the time of first ECG and CK-MB change in the survivors. Twenty-seven patients showed their first ECG change at $24 \mathrm{hr}$, in three first change was seen at $48 \mathrm{hr}$, and one the first change was evident at $72 \mathrm{hr}$. No surviving patients showed a change in CK-MB at six hours suggesting that in this group the induction of anaesthesia was not associated with myocardial damage. Twenty-three patients of the elevated enzyme group showed their first change at $24 \mathrm{hr}$, with four patients showing their first change at $48 \mathrm{hr}$, and none at $72 \mathrm{hr}$. Twenty-two patients showed a rise in CK-MB levels which correlated with the serial ECG changes including the two deaths.

Figure 2 shows the incidence of new ECG change in relation to pre-operative cardiac history. Thirty-one patients gave a pre-operative history of a previous myocardial infarction or stable angina with or without ECG changes. Twenty-three of this group, including the two 
TABLE II Patient stratification with Goldman risk index

\begin{tabular}{lllllll}
\hline & $\begin{array}{l}\text { Complication } \\
\text { rate }=\%\end{array}$ & Patients & $\begin{array}{l}\text { Expected } \\
\text { complications }\end{array}$ & $\begin{array}{l}\text { Obs. ECG } \\
\text { change }\end{array}$ & $\begin{array}{l}\text { Obs. CK-MB } \\
\text { change }\end{array}$ & $\begin{array}{l}\text { Obs. ECG/CK-MB } \\
\text { change }\end{array}$ \\
\hline Class I & 3 & 25 & 0.75 & $15^{*}$ & $12^{*}$ & $9^{*}$ \\
Class II & 10 & 19 & 1.90 & $12^{*}$ & $12^{*}$ & $8^{*}$ \\
Class III & 30 & 4 & 1.20 & 3 & 3 & 3 \\
Class IV & 75 & 2 & 1.50 & 2 & 2 & 2 \\
\hline
\end{tabular}

*Denotes Chi square significant $P<0.001$.

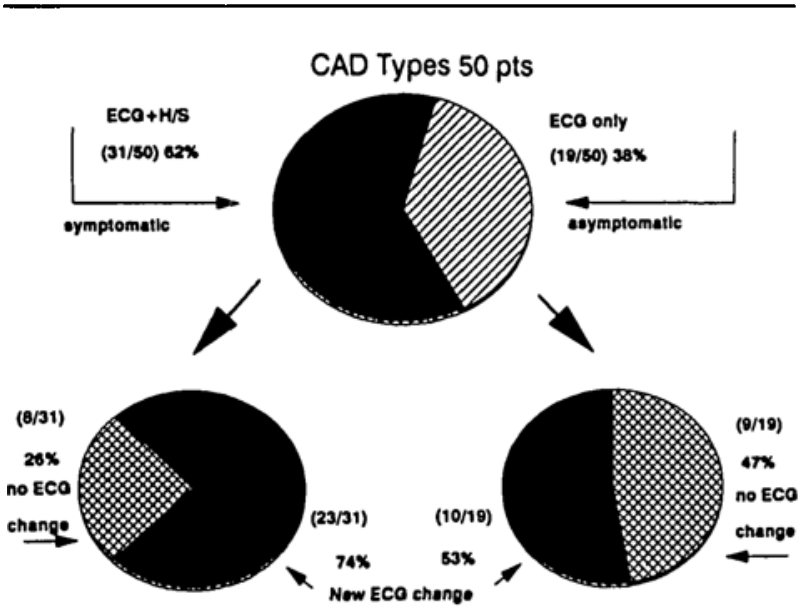

FIGURE 2 Diagram of the incidence of new ECG change in two subpopulations of patients with known coronary artery disease. The occurrence of new ECG change in patients who were symptomatic pre-operatively is not different from that of patients who were asymptomatic. CAD: coronary artery disease. $\mathrm{H} / \mathrm{S}$ : history and symptoms. (H/S = history of MIA stable angina.)

deaths, showed further ECG change. Nineteen patients were asymptomatic preoperatively, with ECG changes only. Of these, ten developed further ECG changes. There was no statistical difference in the incidence of new ECG change in the two groups. Nineteen patients were receiving diuretics; 15 showed further evidence of ECG change. Thirty-one patients were not receiving diuretics and 18 showed further serial ECG change. There was no statistical difference between these two groups.

Thirty-three patients (66\%) showed evidence of serial ECG change. Two patients died in the immediate postoperative period. In the remaining 31 , this serial change lasted more than $48 \mathrm{hr}$ suggesting further myocardial damage. Figure 3 shows the incidence of $Q$ and non- $Q$ ECG and correlative CK-MB change in those patients with serial ECG change. Nineteen patients with further ECG change showed changes suggestive of non- $Q$ wave damage, with 11 having correlative ECG/CK-MB change.

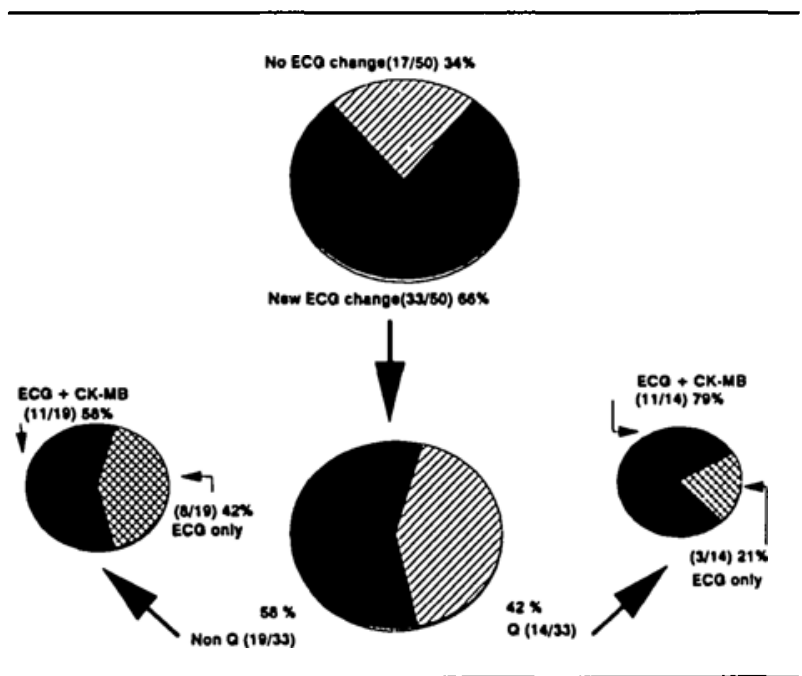

FIGURE 3 Diagram of the distribution of $Q$ and non-Q patterns of new serial ECG change observed post-operatively and their relationship to CK-MB change. The incidence of concurrent change was similar in the two subpopulations.

Fourteen patients showed changes suggestive of $Q$ wave infarction. Of these, 11 showed correlative ECG CK-MB changes. There was no difference in the incidence of $Q$ vs non $Q$ ECG change nor in the incidence of concurrent CK-MB change in these patients with serial ECG change.

The Goldman class I and II risk index underestimated the observed incidence of new ECG, CK-MB change, and new ECG and CK-MB change (Table II) $(P<0.001)$. Only in Goldman class III and IV did the expected and observed complications show no statistical difference. The Cooperman risk index in groups $<0.1,<0.2,<0.3$ significantly underestimated the observed incidence of further ECG evidence of damage (Table III) $(P<0.001$, $<0.001,<0.01$ respectively). The Cooperman risk index groups $<0.1,<0.2$, also underestimated the observed incidence of CK-MB change ( $\mathrm{P}<0.001,<0.01$ respectively). However, combining new ECG and CK-MB changes showed that only in Cooperman risk group $<0.1$ was there a statistically significant underestimate of the observed results $(P<0.001)$. Table IV compares patient 
TABLE II] Patient stratification with the Cooperman risk index

\begin{tabular}{llllll}
\hline $\begin{array}{l}\text { Cooperman } \\
\text { class }\end{array}$ & Patients & $\begin{array}{l}\text { Expected } \\
\text { complications }\end{array}$ & $\begin{array}{l}\text { Obs. ECG } \\
\text { change }\end{array}$ & $\begin{array}{l}\text { Obs. CK-MB } \\
\text { change }\end{array}$ & $\begin{array}{l}\text { Obs. ECG/CK-MB } \\
\text { change }\end{array}$ \\
\hline$<0.1$ & 18 & 1.8 & $9^{*}$ & $10^{*}$ & $8^{*}$ \\
$0.1<0.2$ & 10 & 2.0 & $8^{*}$ & $5^{*}$ & 3 \\
$0.2<0.3$ & 12 & 4.0 & $8^{*}$ & 6 & 4 \\
$0.3<0.4$ & 03 & 1.2 & 3 & 3 & 3 \\
$>0.4$ & 07 & 3.5 & 5 & 5 & 3 \\
\hline
\end{tabular}

*Denotes Chi square $P<0.01$.

TABLE IV Comparison of patient placcment using both Cooperman and Goldman risk indices

\begin{tabular}{l|lllll}
\hline \multirow{2}{*}{$\begin{array}{l}\text { Cooperman } \\
\downarrow\end{array}$} & Goldman $\rightarrow$ & I $(0.03)^{*}$ & II $(0.10)$ & III $(0.30)$ & IV (0.75) \\
\cline { 2 - 6 } & Patients & 25 & 19 & 4 & 2 \\
\hline$<0.1$ & 18 & 16 & 2 & 0 & 0 \\
$<0.2$ & 10 & 5 & 5 & 0 & 0 \\
$<0.3$ & 12 & 4 & 6 & 2 & 0 \\
$<0.4$ & 3 & 0 & 3 & 0 & 0 \\
$>0.4$ & 7 & 0 & 3 & 2 & 2 \\
\hline
\end{tabular}

* Bracketed values indicate the probability of further morbidity.

stratification with both risk indices. The Cooperman Class indices represent the probability of a perioperative complication. Patients ranked as Goldman class I and II showed marked dispersion when ranked with the Cooperman index, with the latter predicting a higher probability of further morbidity. Both indices were similar in assessment of the very sick and the very well but evidenced numerous inconsistencies over the middle ranges.

\section{Discussion}

These findings are at variance with earlier published studies, showing a higher degree of myocardial morbidity than previously described. These results may be related to the design of the study, in that patients were followed prospectively for both serial ECG and CK-MB change, to the population studied, and possibly to the type of surgery. Patients presenting for surgery are subject to stress to the cardiovascular system. In patients with active coronary artery disease this stress may precipitate a further infarct. In preoperative assessments, the probability of further myocardial complications is often based on the Goldman index. ${ }^{7,10}$ This index may not accurately predict risk. It relies on an assessment based on a documented myocardial infarct, and places heavy emphasis on the presence of ventricular beats as a prime indicator of active coronary artery disease. Previous studies have relied on patient symptomatology to initiate further testing to rule out a possible perioperative myocardial infarct. ${ }^{5-8}$ That this may underestimate the true incidence of further myocardial damage has been acknowledged in some studies. ${ }^{5,6}$

When patients with a history of myocardial damage present for major non-cardiac surgery, the basic question would seem to be: "Does the patient have serious coronary artery disease?." The natural progression of coronary artery disease after a myocardial infarct remains unquantified. " Both Goldman and Cooperman indices rely on a positive history of myocardial symptoms and an abnormal ECG. In our study a patient with an abnormal ECG but no symptoms is at no less a risk. Support for this comes from the Framingham Study where it has been shown that up to $40 \%$ of myocardial infarcts in a population of patients with coronary artery disease may be silent, ${ }^{12}$ and that the "non-specific ST-T wave changes" in the absence of symptoms are nonetheless highly specific indicators of subsequent myocardial events.

An ECG at day five has been used to define cardiac morbidity; ${ }^{7}$ however, such an arbitrary choice of time may miss subendocardial damage which may have resolved by this time. Charlson et al. ${ }^{13}$ in a prospective study have shown that an ECG at day five has a reduced sensitivity $(67 \%)$ in diagnosing ECG change compared to serial daily ECG's for the first two days, when sensitivity increases to $96 \%$. The ECG changes in this study are higher than in previous reported studies. This may in part be due to the frequency of serial ECG's in our study. Chamberlain $^{14}$ found a $33 \%$ deterioration in ECGs performed after surgery and again if patients disease 
symptoms warranted it on the third day, in patients with a history of coronary artery diseaes presenting for major non-cardiac surgery.

In a prospective study of orthopaedic patients with a history of coronary artery disease, Knorring ${ }^{15}$ found a $17.7 \%$ rate of reinfarction when assessing daily ECGs. They also noted that myocardial infarction was maximal on the second day. In our study, myocardial damage was maximal in the first $24 \mathrm{hr}$ after the start of anesthesia. Similar findings related to the timing of myocardial damage in the first $24 \mathrm{hr}$ have been noted in other studies. ${ }^{13,16-18}$ The rise in CK-B in relation to myocardial infarction has been documented, ${ }^{19}$ and the specificity of $\mathrm{CK}-\mathrm{MB}$ in diagnosing myocardial damage in the presence of general surgery has been validated. ${ }^{20,21}$ Serum CK$\mathrm{MB}$ and $\mathrm{CK}-\mathrm{BB}$ may rise transiently after surgery up to levels of $12 \mathrm{I} \cdot \mathrm{U} \cdot \mathrm{L}^{-1}$, with a rise noted at two to four hours, with a return to normal by $24 \mathrm{hr}$. These CK isoenzymes may also be elevated with liver damage, pneumonia, and brain trauma. Caution should be exercised in the diagnosis of myocardial infarction based on $\mathrm{CK}$ isoenzyme alone after surgery. ${ }^{22}$ In this study all patients with CK-MB elevation showed serial rise at $24 \mathrm{hr}$ and beyond and in $22 / 50(44 \%)$ there was concurrent serial ECG change. Myocardial morbidity was high. The prospective nature of this study, and the type of surgery, and the patient population may explain in part the higher incidence of detected morbidity. Similar findings of high morbidity have been reported. ${ }^{23}$ Roy et al. ${ }^{1}$ noted ischaemia on the ECG associated with intubation of the trachea. If such ischaemia were sufficient to cause myocardial damage, then a rise in CK-MB would be seen at six hours. In this study no evidence could be found of such a rise. In this study both ECG and enzyme changes were effected in the majority of patients, $87 \%$ and $85 \%$ respectively by $24 \mathrm{hr}$. The results of $24 \mathrm{hr}$ Holter monitoring and the non-invasive blood pressure monitoring presented in a subsequent paper may help gain an understanding of the mechanism of such damage. ${ }^{9}$

The numbers in this study are small compared with the series of Goldman et al. ${ }^{7}$ and Tarhan et al. ${ }^{5}$ The majority of the patients in this group underwent vascular surgery and these patients could represent a sub-group at one extreme of the population of patients with concurrent coronary artery disease, presenting for major surgery. The Goldman risk index has been shown to underestimate the incidence of further myocardial damage in patients having vascular surgery. ${ }^{18}$ Such a population would have a spread of severity of jepordised myocardium, ranging from good collateral supply to critical perfusion/demand imbalance. The impaired activity of these patients as a whole may mask the usual symptoms associated with severe coronary artery disease. Excessive blood loss, which is common in vascular surgery, may lead to a functional hypoxaemia in this group despite adequate blood transfusion, due in part to effete cells in the transfusion and depleted 2,3 DPG stores (which may require up to $24 \mathrm{hr}$ for regeneration) in the transfused red cells. All serum haemoglobin concentrations in this study were within the normal range at 24,48 , and $72 \mathrm{hr}$. Vascular surgery may also be associated with a relative hypercoagulopathy compared with other types of surgery, due to increased vascular endothelial trauma. In this study this was not investigated. A previous history of left ventricular failure may be an important risk factor in predicting further myocardial damage. The two deaths occurred in patients who had suffered left ventricular failure in the week or less before surgery. In this study, the precise reasons why patients were recieving diuretics could not be documented. There was no statistical difference in the incidence of new ECG changes in the diuretic and non-diuretic group.

Both the Cooperman and Goldman risk indices assign variables with a rank order of significance. These variables depend heavily on the expression of clinical symptoms and signs. However, patients with vascular disease may not be capable, due to their disease state, of manifesting the full extent of their coronary artery disease, in terms of both symptoms and signs. In this study there was no statistical difference in incidence of further myocardial damage in the symptomatic and symptomless patients. There was no statistical difference in the incidence of $Q$, non- $Q$, and correlative ECG/ CK-MB changes. The abnormal ECG in a symptomless patient may not be as non-specific as commonly assumed. ${ }^{24.25} \mathrm{~A}$ change in the relative weight of the abnormal ECG in the Cooperman formula may lead to an improvement in the accuracy of this risk index.

Patients' symptoms and a multifactorial index may not provide an adequate basis for risk assessment of further myocardial damage, when patients with coronary artery disease present for major surgery. Risk assessment may best be evaluated in relation to each patient's myocardial function, and incidence of myocardial ischaemia just prior to surgery. Abnormalities in the ECG in the absence of symptoms should not be ignored, as they may be significant indicators of nasient myocardial dysfunction.

\section{References}

1 Roy WL, Edelist G, Gilbert B. Myocardial ischacmia during non cardiac surgical procedures in patients with coronary artery discase. Anesthesiology 1979; 51 : 393-7.

2 Halter JB, Pflug AE, Porte D. Mechanism of plasma catecholamine incrcases during surgical stress in man. J Clin Endocrinal 1977; 45: 936-44. 
3 Bland RD, Shoemaker WC. Common physiologic pattcrns in general surgical patients: hemodynamic and oxygen transport changes during and after operation in patients with and without associated medical problems. Surg Clin North Am 1985; 65: 793-809.

4 Traynor $C$, Hall GM. Endocrine and metabolic changes during surgery: anaesthetic implications. $\mathrm{Br} \mathrm{J}$ Anaesth 1970; 53: 152-60.

5 Tarhan S, Moffitt EA, Taylor WF, Giuliani ER. Myocardial infarction after general anaesthesia. JAMA 1972; 220: 1451-4.

6 Steen PA, Tinker JH, Tarhan S. Myocardial reinfarction after anaesthesia and surgery. JAMA 1978; 239: 2566-70.

7 Goldman L, Caldera DL, Nussbaum SR et al. Multifactorial index of cardiac risk in non cardiac surgical procedurcs. N Engl J Med 1977; 297: 845-50.

8 Cooperman M, Pflug B, Martin EW, Evans WE. Cardiovascular risk factors in patients with peripheral vascular disease. Surgery 1978; 84: 505-9.

9 Seegobin RD, Wilmshurst TH, Johnston J et al. Early postoperative myocardial morbidity in patients with coronary artery disease undergoing major non cardiac surgery: correlation with perioperative ischaemia. Can J Anaesth (In this issue) (In Press).

10 Goldman $L$, Wolf MA, Braunwald E. General anaesthesia and noncardiac surgery in patients with heart disease. In: Braunwald E (Ed.). Heart Disease 1988; 1693-705.

11 Moss AJ, Benhorin J. Prognosis and management after a first myocardial infarction. N Engl J Med 1990; 322: 743-53.

12 Kannel WB, Abbott RD. Incidence and prognosis of unrecognised myocardial infarction: an update on the Framingham Study. N Engl J Med 1984; 311 : 1144-7.

13 Charlson ME, MacKenzie CR, Ales K, Gold JP, Fairclough $G$, Shires $G T$. Surveillance for post operative myocardial infarction after noncardiac operations. Surg Gynecol Obstet 1988; 167: 407-14.

14 Chamberlain DA, Edmonds-Seal J. The effects of surgery under general anaesthesia on the ischemic electrocardiogram. Am Heart J 1965; 70: 834-5.

15 Von Knorring J. Postoperative myocardial infarction: a prospective study in a risk group of surgical patients. Surgery 1981; 90: 55-60.

16 Raby KE, Goldman L, Creager MA et al. Correlation between preoperative ischemia and major cardiac events after peripheral vascular surgery. N Engl J Med 1989; 321: 1296-1300.

17 Charlson ME, Ales $K L$, Simon R, MacKenzie CR. Why predictive indexes perform less well in validation studies: is it magic or methods? Arch Intern Med 1987; 147: 2155-61.
18 Jeffrey CC, Kunsman J, Cullen D, Brewster DC. A prospective evaluation of cardiac risk. Anesthesiology 1983; 58: 462-4.

19 Gerhardt W, Waldenstrom J, Horder $M$ et al. Creatine kinase and creatine kinase $B$ subunit activity in serum in cases of suspected myocardial infarction. Clin Chem 1982; 28: 277-83.

20 Roberts $R$, Gowda KS, Ludbrook PA, Sobel BE. Specificity of clevated serum $\mathrm{MB}$ creatin phosphokinase activity in the diagnosis of acute myocardial infarction. Am J Cardiol 1975; 36: 433-7.

21 Clayman RV, Ortlip SA, Eckfeldt JH. The diagnostic specificity of creatine kinase isoenzymes after transurethral operations. J Urol 1983; 130: 279-82.

22 Tsung $S H$. Several conditions causing elevation of serum CK-MB and CK-BB. Am J Clin Pathol 1981; 75: 711-5.

23 Fleisher LA, Rosenbaum SH, Barash PG. Preoperative silent ischemia is a predictor of postoperative cardiac events in patients undergoing elective noncardiac surgery. Proceedings 12th Annual Meeting Society of Cardiovascular Anesthestists 1990; 98.

24 Kannel WB. Common electrocardiographic markers for subsequent clinical coronary events. Circulation 1984; 75(Suppl): 25-7.

25 Kannel WB, Anderson K, McGee DL, Degatano LS, Stampfer $M J$. Nonspecific electrocardiographic abnormality as a predictor of coronary artery disease: The Framingham Study. Am Hcart J 1987; 113: 370. 